\title{
Genetic regulation of fatty acid modifying enzyme from Staphylococcus aureus
}

\author{
N. R. CHAMBERLAIN and B. IMANOEL \\ Department of Microbiology/lmmunology, Kirksville College of Osteopathic Medicine, Kirksville, MO 63501, \\ USA
}

\begin{abstract}
Fatty acid modifying enzyme (FAME) is an extracellular enzyme that inactivates staphylocidal lipids by catalysing the esterification of these lipids to cholesterol. In-vitro expression of FAME began at the start of the stationary phase. This expression of FAME was very similar to other staphylococcal extracellular proteins controlled by the global regulators Agr and Sar. A Staphylococcus aureus strain ISP546 (Agr ${ }^{-}$) produced c. $80 \%$ less FAME than an isogenic Agr $^{+}$strain ISP479C. Similar results were obtained with the isogenic $\mathrm{Agr}^{+} / \mathrm{Agr}^{-}$strain pair RN6390 and RN6911. A S. aureus strain R $\left(\mathrm{Sar}^{-}\right)$produced c. $86 \%$ less FAME than an isogenic $\mathrm{Sar}^{+}$strain RN6390. However, lipase assays on the same culture filtrates from the $\mathrm{Sar}^{+} / \mathrm{Sar}^{-}$strains did not demonstrate any affect on lipase production by the sar mutation.
\end{abstract}

\section{Introduction}

Certain neutral lipids are bactericidal to gram-positive organisms in vitro [1-3]. These bactericidal neutral lipids include long-chain fatty acids and monoglycerides. Previous studies have also demonstrated that the elimination of Staphylococcus aureus within murine abscesses is mediated by the production of long-chain fatty acids and 1- and 2-monoglycerides [1-3]. Longchain fatty acids and monoglycerides comprised c. $40 \%$ (by dry weight) of the neutral lipids obtained from an abscess [4]. The amount of neutral lipids found in $S$. aureus murine abscesses [4] (90\% neutral lipids; $10 \%$ phosphatides and glycolipids) is much higher than is observed in normal tissues [5] (15-40\% neutral lipids; $60-85 \%$ phosphatides and glycolipids). Production of these neutral lipids occurs c. $24 \mathrm{~h}$ after abscess formation [1].

Fatty acid modifying enzyme (FAME) is an extracellular staphylococcal protein that has been shown to inactivate the bactericidal activity of fatty acids $[2,6]$. FAME catalyses the esterification of alcohols (e.g., cholesterol, ethanol) with fatty acids [6] (e.g., plamitate, laureate, oleate). The esters resulting from this reaction are not bactericidal. About $80 \%$ of the $S$. aureus strains tested thus far produce FAME [7]. It has also been shown that FAME-producing strains of $S$. aureus are more invasive in a murine model [6].

Other investigators have demonstrated the importance

Received 6 June 1995; revised version accepted 5 Aug. 1995.

Corresponding author: N. R. Chamberlain. of global regulators in controlling the expression of several staphylococcal extracellular proteins [8-20]. Two of these regulatory elements, the accessory gene regulator (Agr) and the staphylococcal accessory regulator (Sar), control expression of exoproteins by transcriptional control $[13,14]$. Several of these extracellular proteins are important virulence factors (e.g., $\alpha$ toxin, enterotoxins, toxic shock syndrome toxin) and the timing of expression of these factors may prolong the organism's ability to survive in the host.

Mutations in the $\mathrm{Agr}$ locus eliminate expression of some of these exoproteins (e.g., $\alpha$ toxin, serine protease, $\delta$ toxin and toxic shock syndrome toxin). These proteins are called class I Agr-regulated proteins. Other exoproteins are still produced in the $\mathrm{Agr}^{-}$strains but at much lower levels (e.g., nuclease, lipase, $\beta$ toxin and enterotoxin B) and are called class II Agr-regulated proteins. This study examined the effects of mutation of the agr or sar locus on FAME expression and showed that it is a class II Agrregulated protein.

\section{Materials and methods}

\section{Bacterial strains}

$S$. aureus strain $18 \mathrm{Z}$ was a kind gift from Dr F. A. Kapral and has been characterised previously [21]. $S$. aureus strains ISP479C $\left(\mathrm{Agr}^{+}\right), \operatorname{ISP546}\left(\mathrm{Agr}^{-}\right)$, RN6390 ( $\left.\mathrm{Agr}^{+}\right)$and RN6911 (Agr ${ }^{-}$) were used to determine the role of the accessory gene regulator (Agr) in FAME production. The above isogenic strain pairs were kind gifts from Dr J. J. Iandolo (ISP479C/ 
ISP546) [11, 20] and Dr R. P. Novick (RN6390/ RN6911) $[16,22]$. In summary, the $\mathrm{Agr}^{-}$strains produce greatly reduced amounts of lipase, $\alpha$ toxin, protease and nuclease. The $\mathrm{Agr}^{-}$strain (ISP546) was made by insertion of the transposon Tn551 in the agr locus. The $\mathrm{Agr}^{+}$strain (ISP479C) was obtained by curing ISP546 of the transposon in Iandolo's laboratory. Removal of the entire agr locus from RN6390 and replacing it with a tetracycline resistance gene resulted in an $\mathrm{Agr}^{-}$strain, RN6911 [16, 22].

$S$. aureus mutant $\mathrm{R} \mathrm{Sar}^{-}$was a kind gift from $\mathrm{Dr} \mathrm{A}$. L. Cheung $[13,14]$. The mutant $R$ strain was produced by placing Tn917LTV1 in the sar locus of RN6390 $\left(\operatorname{Sar}^{+}\right)$.

In all three strain pairs, $\alpha$ toxin was expressed in the $\mathrm{Sar}^{+}$and $\mathrm{Agr}^{+}$strains but was not detected in the $\mathrm{Sar}^{-}$ and $\mathrm{Agr}^{-}$strains as has been reported previously (data not shown) $[8,16,18]$

\section{FAME assay}

The samples $(5 \mu \mathrm{l})$ to be assayed were diluted with $95 \mu$ of $20 \mathrm{mM}$ MES, $170 \mathrm{mM} \mathrm{NaCl}$, pH 6.0 (MES$\mathrm{NaCl}$ ) unless otherwise indicated. To the diluted filtrate $(100 \mu \mathrm{l})$ was added $5 \mu \mathrm{l}$ of acetone containing $\left[7-{ }^{3} \mathrm{H}\right]$ cholesterol (200000 dpms; sp. act. $=23.8 \mathrm{Ci} /$ mmol; New England Nuclear, Wilmington, DE, USA) and oleic acid $2.5 \mu \mathrm{g}$. Samples were incubated for $30 \mathrm{~min}$ at $37^{\circ} \mathrm{C}$. The lipids were then extracted from the solution with $200 \mu$ l of ethyl ether:methanol (6:1, EE:M). The lower phase was discarded and the upper organic phase was dried in a stream of nitrogen gas. The dried lipids were then suspended in $100 \mu l$ of hexane:ethyl ether:glacial acetic acid (73:25:2; $\mathrm{H}: \mathrm{EE}: \mathrm{AA})$. The cholesterol ester was separated from the radiolabelled cholesterol with silica gel columns and a solvent system used for TLC to separate cholesterol esters from fatty acids and cholesterol as described previously $[5,23]$. Slurries of silica gel (average particle size $40 \mu \mathrm{m}$; VWR Scientific, St Louis, MO, USA) in H:EE:AA were used to make 0.6 -g columns (dry weight; $5.3 \mathrm{~cm} \times 0.5 \mathrm{~cm}$ ) in $23-\mathrm{cm}$ Pasteur pipettes plugged with siliconised glass wool. The suspended samples were placed on the column and the cholesterol esters were eluted in $2 \mathrm{ml}$ of $\mathrm{H}$ :EE:AA. The eluant was collected in liquid scintillation vials and $10 \mathrm{ml}$ of scintillation fluid (ScintiSafe Econo F; Fisher, St Louis, MO, USA) were added. Radioactivity (cpm) of the samples was measured in a liquid scintillation counter as a direct measure of FAME activity (esterification of cholesterol with oleic acid).

\section{Effects of agr and sar mutations on FAME production}

Strains ISP479C (Agr $\left.{ }^{+}\right), \quad$ ISP546 (Agr $\left.{ }^{-}\right), \quad$ RN6390 $\left(\mathrm{Agr}^{+}\right)$and $\mathrm{RN} 6911\left(\mathrm{Agr}^{-}\right)$were used to determine the role of agr in FAME production. The bacteria from an overnight culture $(0.5 \mathrm{ml})$ were pelleted by centrifugation $\left(12000 \mathrm{~g} ; 10 \mathrm{~min}, 4^{\circ} \mathrm{C}\right)$ and then washed with sterile Trypticase Soy Broth (TSB, Difco) $0.5 \mathrm{ml}$. This was repeated twice before addition of the organisms to pre-warmed $\left(37^{\circ} \mathrm{C}\right)$ TSB $(50 \mathrm{ml})$ in a 250-ml Erlenmeyer flask. The cultures were incubated at $37^{\circ} \mathrm{C}$ and aerated by shaking at $110 \mathrm{rpm}$ (reciprocating shaker). At various times, $1 \mathrm{ml}$ samples of the cultures were removed, the optical density at $600 \mathrm{~nm}$ $\left(\mathrm{OD}_{600}\right)$ was determined, and filtrate was collected (0.2 $\mu \mathrm{m}$; Acrodisc; Gelman, Ann Arbor, MI, USA). The filtrates were then stored at $-20{ }^{\circ} \mathrm{C}$ until they were assayed for FAME activity as described above.

Strains RN6390 $\left(\mathrm{Sar}^{+}\right)$, and R (Sar ${ }^{-}$) were incubated and assayed for FAME activity as described above. The $\mathrm{Sar}^{-} / \mathrm{Sar}^{+}$strain pair was also assayed for lipase activity as described below. Antibiotics were used only to passage the $\mathrm{Sar}^{-}$and $\mathrm{Agr}^{-}$strains.

\section{Lipase assay}

The assay was performed as previously described with thin layer chromatography Silica Gel H plates (Analtech; Newark, DE, USA) to separate products from substrate [24].

\section{Results}

\section{Genetic regulation of FAME expression}

All three isogenic strain pairs were incubated in TSB at $37^{\circ} \mathrm{C}$. Samples were taken at various time intervals to determine when and how much FAME activity was present in the culture filtrates.

The $\mathrm{Agr}^{-} / \mathrm{Agr}^{+}$strains ISP546/ISP479C both grew exponentially for $2 \mathrm{~h}$ followed by a slower growth phase for about another $4 \mathrm{~h}$. Growth of both strains reached a plateau at $c$. $6 \mathrm{~h}$. There was no significant difference between the growth curves of the $\mathrm{Agr}^{-}$and $\mathrm{Agr}^{+}$strains (Fig. 1)

Assays for FAME activity in the culture filtrates were then conducted to see if mutation in the agr locus had any effect on FAME production. FAME activity expressed by the $\mathrm{Agr}^{+}$strain (ISP479C) increased rapidly from 2 to $7 \mathrm{~h}$ of growth (Fig. 1). A plateau was reached at 7-9 $\mathrm{h}$ followed by a decrease in FAME activity after growth for $9 \mathrm{~h}$. The greatest increase in FAME activity began during early stationary phase (Fig. 1). Similar results were obtained with a wild-type FAME-producing strain of $S$. aureus 18Z [21] (data not shown).

The $\mathrm{Agr}^{-}$strain (ISP546) expressed little FAME activity until c. $7 \mathrm{~h}$ of growth (Fig. 1). FAME activity did increase between 1 and $2 \mathrm{~h}$ of incubation although the amount of FAME produced was less than that produced by the $\mathrm{Agr}^{+}$strain. Significant increases in 


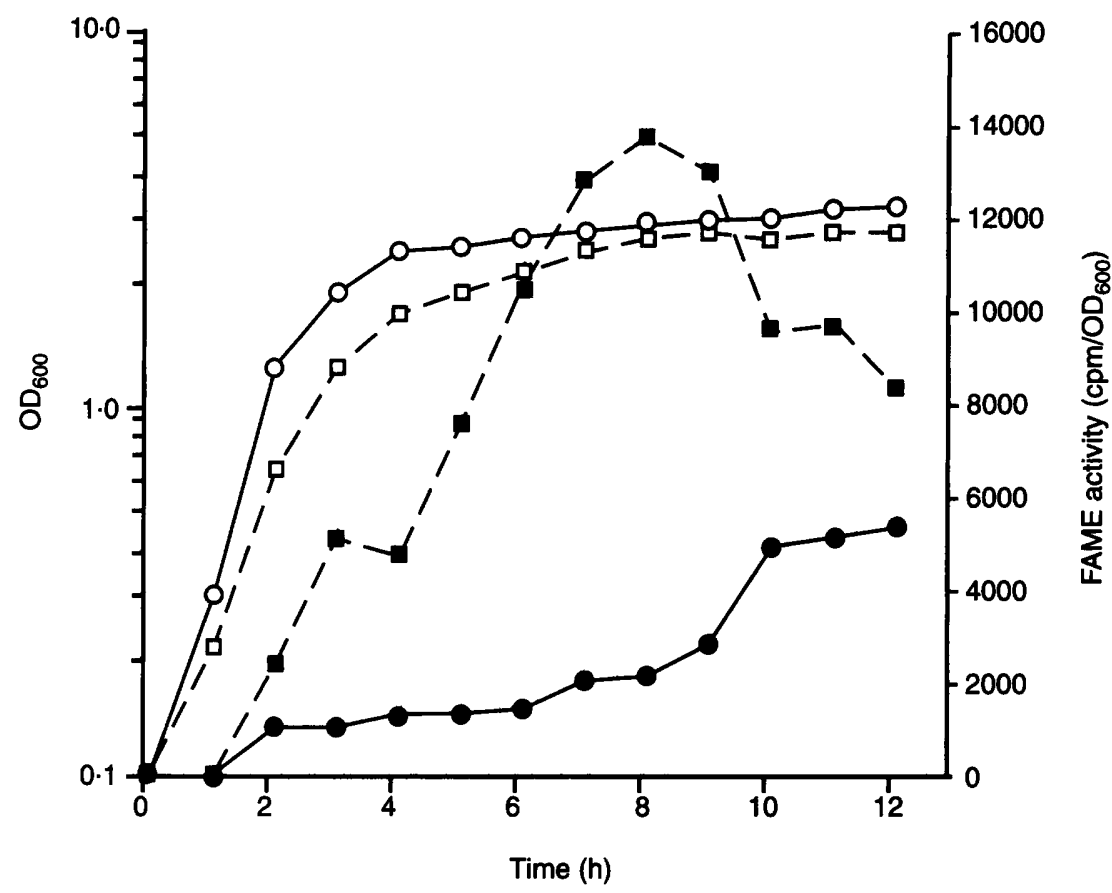

Fig. 1. FAME activity of $S$. aureus strains ISP479C ( $\left.\mathrm{Agr}^{+} ; \mathbf{\square}\right)$ and ISP546 $\left(\mathrm{Agr}^{-} ; 0\right)$ versus time of incubation and the growth curve of ISP479C $\left(\mathrm{Agr}^{+} ; \square\right)$ and ISP546 ( $\left.\mathrm{Agr}^{-} ; O\right)$.

FAME production by the $\mathrm{Agr}^{-}$strain did not occur until late in the stationary phase. When FAME activities at $8 \mathrm{~h}$ were compared, the $\mathrm{Agr}^{-}$strain expressed $84 \%$ less FAME than the $\mathrm{Agr}^{+}$strain.

Similar results were obtained with the other $\mathrm{Agr}^{-} /$ $\mathrm{Agr}^{+}$strain pair (RN6911/RN6390). This $\mathrm{Agr}^{+}$strain also did not express FAME until early in stationary phase (Fig. 2). The $\mathrm{Agr}^{-}$strain began expression of
FAME in early stationary phase $(2-3 \mathrm{~h})$ although the rate and amount of FAME produced were less. An increase in FAME production by the $\mathrm{Agr}^{-}$strain was observed late in stationary phase. At $8 \mathrm{~h}$ of growth the $\mathrm{Agr}^{-}$strain expressed 50\% less FAME than the $\mathrm{Agr}^{+}$ strain. The reduction in FAME expression that occurred in the stationary phase was not significant.

The $\mathrm{Sar}^{-} / \mathrm{Sar}^{+}$strain pair (R/RN6390) was then

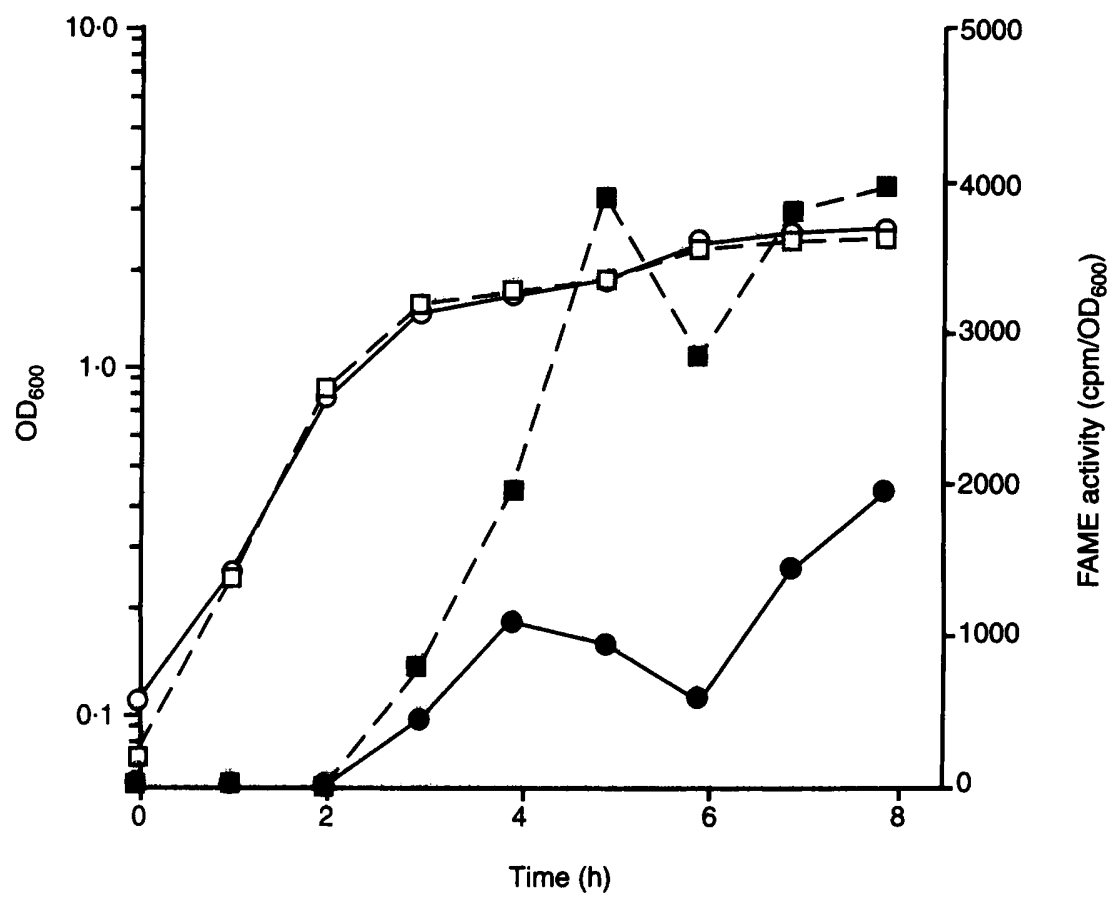

Fig. 2. FAME activity of $S$. aureus strains $\mathrm{RN} 6390\left(\mathrm{Agr}^{+} ; 0\right)$ and $\mathrm{RN} 6911\left(\mathrm{Agr}^{-}\right.$; 9$)$ versus time of incubation and the growth curve of RN6390 ( $\left.\mathrm{Agr}^{+} ; \square\right)$ and RN6911 ( $\left.\mathrm{Agr}^{-} ; \mathrm{O}\right)$. 
examined to see what affect, if any, this global regulator had on FAME production. The $\mathrm{Sar}^{-}$mutant expressed FAME activity in early stationary phase; however, the rate and amount of FAME produced were less than those produced by the $\mathrm{Sar}^{+}$strain (Fig. 3). After incubation for $8 \mathrm{~h}$ the $\mathrm{Sar}^{-}$strain produced $86 \%$ less FAME than the $\mathrm{Sar}^{+}$strain. Lipase activity after incubation for $8 \mathrm{~h}$ was not affected (data not shown).

\section{Discussion}

These studies show that FAME expression is significantly reduced in $\mathrm{Agr}^{-}$and $\mathrm{Sar}^{-}$strains, and also demonstrate that FAME is a class II Agr-regulated exoprotein.

Previous studies have demonstrated the importance of certain staphylocidal neutral lipids (fatty acids and monoglycerides) in destroying $S$. aureus in murine abscesses [1-3]. The staphylocidal lipids represent $c$. $60 \%$ (by weight) of the neutral lipid extracted from abscesses. Shortly after abscess formation $(24 \mathrm{~h})$ these staphylocidal lipids are produced by the host [3]. One way $S$. aureus may prolong its survival in an abscess is to inactivate the staphylocidal lipids.

FAME has been shown to protect $S$. aureus against the bactericidal effects of fatty acids by esterification of the staphylocidal lipids to cholesterol [6]. Previous studies have also shown a positive correlation between the ability of a strain to produce FAME and its ability to cause invasive disease [6].

This study was conducted to determine whether FAME expression was controlled by a staphylococcal global regulator. If FAME is important in the survival of staphylococci in an abscess then the timing of expression may be as important as the amount of FAME produced. As mentioned earlier, staphylocidal fatty acids do not occur in an abscess until about $24 \mathrm{~h}$ after abscess formation. To save valuable energy, it could possibly benefit the bacterium to delay FAME production until just before it is needed most.

At least three different global regulators have been described: the accessory gene regulator (Agr) [16-19], staphylococcal accessory gene regulator (Sar) $[13,14]$ and the extracellular gene regulator (Xpr) [20]. Each one is able to delay the expression of many extracellular proteins until the early stationary phase of growth. The Agr and Sar global regulators have been very well described $[13,14,16-19]$. Isogenic mutants and wild-type strains are readily available and, therefore, were used in this study.

In these experiments it was demonstrated that mutation of the agr locus drastically affects FAME production (Figs 1 and 2). Not all strains are affected in the same way, as can be seen by differences in the amount of inhibition of FAME production when the two different Agr strain pairs are compared (Figs 1 and 2). This strain-dependent difference in Agr control of exoproteins has been described previously [14].

Another difference noted between the two $\mathrm{Agr}^{+}$strains was the time at which FAME activity was detectable. The ISP479C strain produced detectable FAME activity at $1-2 \mathrm{~h}$, whereas strain RN6390 did not produce detectable levels of FAME until 2-3 h of

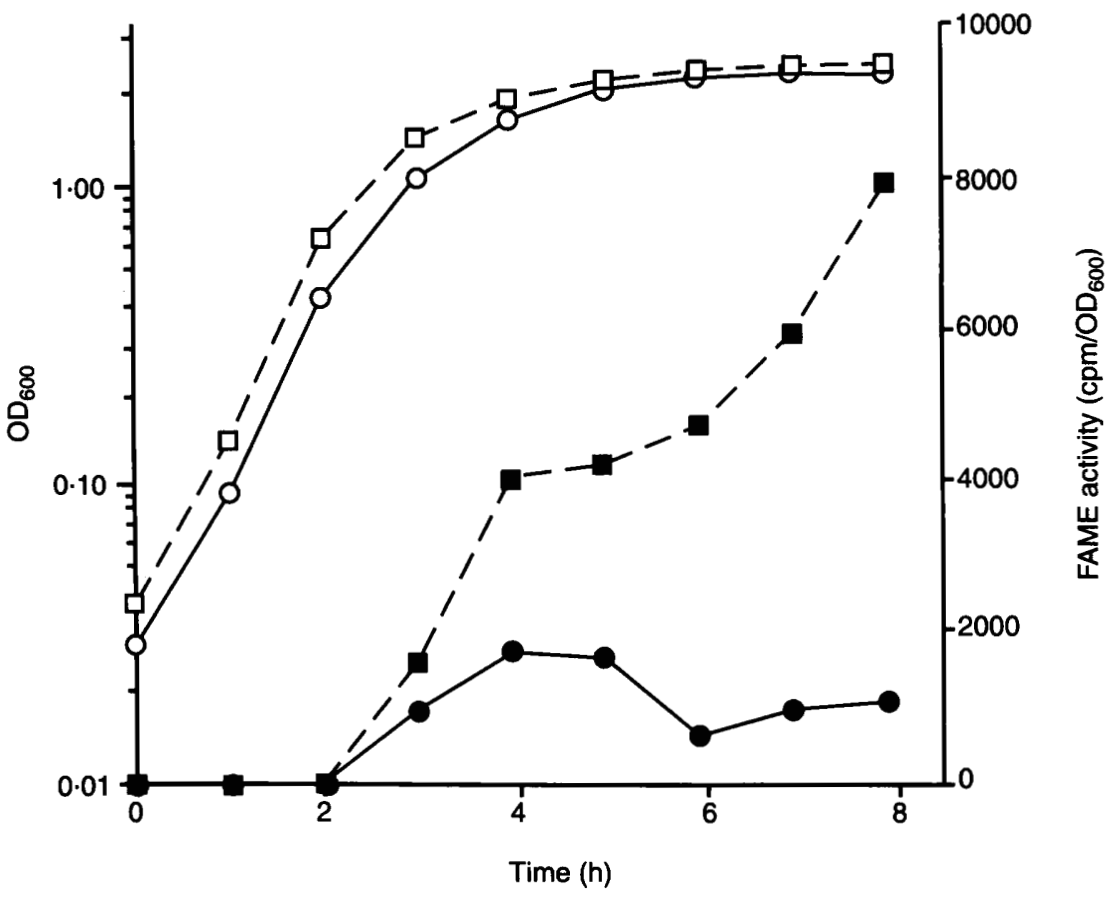

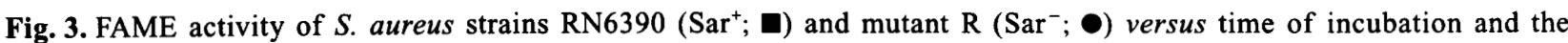

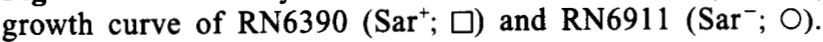


growth. This difference does not appear to be due to different growth rates or to differences in optical densities at time zero (Figs 1,2 and 3).

The $\mathrm{Agr}^{-}$strains began production of FAME early in the stationary phase of growth; however, the rate and amount of FAME produced were much less (Figs 1 and 2). Expression of FAME is not totally eliminated as has been described for class I Agr-regulated extracellular proteins ( $\alpha$-haemolysin, TSST-1, $\delta$-haemolysin) $[16,18]$. However, the control of FAME production by the agr locus is similar to class II exoproteins (nuclease, $\beta$-haemolysin, lipase) in that the protein is still expressed but at much lower levels (50-84\% less) $[16,18]$. Other Agr class II proteins have shown similar levels of expression in $\mathrm{Agr}^{-}$ strains and this is most likely due to the fact that regulation by this locus is leaky $[16,18]$.

Mutation of the sar locus also affects FAME production. Much less FAME was produced $(86 \%$ less) in the mutant when compared to the $\mathrm{Sar}^{+}$strain. These results are different from those reported for lipase and protease [14]. Previous studies have shown that sar mutants produce as much or more of these enzymes than the isogenic $\mathrm{Sar}^{+}$strain. This increase in protease may also explain why no late stationary phase increase in FAME activity was noted in the $\mathrm{Sar}^{-}$strain.

Other investigators have provided evidence that the agr locus may be controlled by the sar locus [13]. If a sar mutation occurs then the expression of Agrregulated proteins will be affected. Much like $\alpha$ toxin, FAME expression is decreased when the sar locus is mutated. However, low levels of FAME would still be expressed due to the fact that Agr does not completely eliminate expression of class II proteins.

Finally, it is hoped to purify FAME, characterise the enzyme and then clone the FAME gene in Escherichia coli; and eventually to produce a strain of $S$. aureus unable to express FAME and examine the effects of this mutation in a murine abscess model [4].

We thank Drs R. P. Novick, J. J. Iandolo, F. A. Kapral and A. L. Cheung for the use of their bacterial strains. We are grateful to Drs N. Sargentini and G. Tritz for their helpful discussions. We also thank Kathy Krog for excellent computer and typing assistance. This study was partially supported by a Warner fund grant from KCOM and Public Health Service grant R15Al-3119 from the National Institute of Allergy and Infectious Diseases to N.R.C.

\section{References}

1. Shryock TR, Dye ES, Kapral FA. The accumulation of bactericidal lipids in staphylococcal abscesses. $J$ Med Microbiol 1992; 36: 332-336.

2. Engler HD, Kapral FA. The production of a bactericidal monoglyceride in staphylococcal abscesses. $J$ Med Microbiol 1992; 37: 238-244.

3. Shryock TR, Kapral FA. The production of bactericidal fatty acids from glycerides in staphylococcal abscesses. $\mathrm{J} \mathrm{Med}$ Microbiol 1992; 36: 288-292.

4. Dye ES, Kapral FA. Characterization of a bactericidal lipid developing within staphylococcal abscesses. Infect Immun 1981; 32: 98-104.

5. Kates M. Laboratory techniques in biochemistry and molecular biology, vol 3, part 2. Techniques of lipidology: isolation, analysis and identification of lipids. 2nd edn. New York, Elsevier. 1986: 186.

6. Mortensen JE, Shryock TR, Kapral FA. Modification of bactericidal fatty acids by an enzyme of Staphylococcus aureus. J Med Microbiol 1992; 36: 293-298.

7. Kapral FA, Smith S, Lal D. The esterification of fatty acids by Staphylococcus aureus fatty acid modifying enzyme (FAME) and its inhibition by glycerides. J Med Microbiol 1992; 37: 235-237.

8. Abbas-ali B, Coleman G. The characteristics of extracellular protein secretion by Staphylococcus aureus (Wood 46) and their relationship to the regulation of alpha-toxin formation. I Gen Microbiol 1977; 99: 277-282.

9. Arvidson S, Janzon L, Lofdahl S. The role of the delta-lysin gene (hld) in the agr-dependent regulation of exoprotein synthesis in Staphylococcus aureus. In: Novick RP (ed) Molecular biology of the Staphylococci. New York, VCH Publishers. 1990: 419-431.

10. Arvidson S, Janzon L, Lofdahl S, Morfeldt E. The exoprotein regulatory region exp of Staphyloccus aureus. In: Butler LO, Harwood C, Moseley BEB (eds) Genetic transformation and expression. Andover, Intercept Ltd. 1989: 511-518.

11. Bayles $\mathrm{KW}$, Iandolo JJ. Genetic and molecular analyses of the gene encoding staphylococcal enterotoxin D. J Bacteriol 1989; 171: 4799-4806.

12. Bjorklind A, Arvidson S. Mutants of Staphylococcus aureus affected in the regulation of exoprotein synthesis. FEMS Microbiol Lett 1980; 7: 203-206.

13. Cheung AL, Projan SJ. Cloning and sequencing of sarA of Staphylococcus aureus, a gene required for the expression of agr. J Bacteriol 1994; 176: 4168-4172.

14. Cheung AL, Ying P. Regulation of alpha- and beta-hemolysins by the sar locus of Staphylococcus aureus. J Bacteriol 1994; 176: $580-585$.

15. Janzon L, Arvidson S. The role of the delta-lysin gene (hld) in the regulation of virulence genes by the accessory gene regulator (agr) in Staphylococcus aureus. EMBO J 1990; 9: 1391-1399.

16. Kornblum J, Kreiswirth BN, Projan SJ, Ross H, Novick RP. Agr: a polycistronic locus regulating exoprotein synthesis in Staphylococcus aureus. In: Novick RP (ed) Molecular biology of the staphylococci. New York, VCH Publishers, Inc. 1990: 373-402.

17. Morfeldt E, Janzon L, Arvidson A, Lofdahl S. Cloning of a chromosomal locus (exp) which regulates the expression of several exoprotein genes in Staphylococcus aureus. Mol Gen Genet 1988; 211: 435-440.

18. Novick R, Kornblum J, Kreiswirth B, Projan S, Ross H. agr: a complex locus regulating post-exponential phase exoprotein synthesis in Staphylococcus aureus. In: Butler LO, Harwood C, Moseley BEB (eds) Genetic transformation and expression. Andover. Intercept Ltd. 1989: 495-510.

19. Peng H-L, Novick RP, Kreiswirth B, Kornblum J, Schlievert P. Cloning, characterization, and sequencing of an accessory gene regulator (agr) in Staphylococcus aureus. J Bacteriol 1988; 170: $4365-4372$.

20. Smeltzer MS, Hart ME, Iandolo JJ. Phenotypic characterization of $x p r$, a global regulator of extracellular virulence factors in Staphylococcus aureus. Infect Immun 1993; 61: 919-925.

21. Kanai K, Kondo E. Antibacterial and cytotoxic aspects of long-chain fatty acids as cell surface events: selected topics. Jpn J Med Sci Biol 1979; 32: 135-174.

22. Recsei P, Kreiswirth B, O'Reilly M, Schlievert P, Gruss A, Novick RP. Regulation of exoprotein gene expression in Staphylococcus aureus by agr. Mol Gen Genet 1986; 202: 919-925.

23. Chautan M, Termine E, Nalbone G, LaFont H. Acyl-coenzyme A: cholesterol acyltransferase assay: silica gel column separation of reaction products. Anal Biochem 1988; 173: 436-439.

24. Rollof J, Hedstrom AS, Nilsson-Ehle P. Positional specificity and substrate preference of purified Staphylococcus aureus lipase. $B B A$ 1987; 921: 370-377. 